\title{
The hydrothermal component in ferromanganese nodules from the southeast Pacific Ocean
}

\author{
Joy C. CHEN* and ROBERT M. OWEN** \\ Department of Geological Sciences, The University of Michigan, Ann Arbor, MI 48109, U.S.A.
}

(Received April 27, 1988; accepted in revised form April 3, 1989)

\begin{abstract}
Statistical analyses of geochemical data from ferromanganese nodule samples representing a broad area of the southeast Pacific Ocean indicate nodule compositions are controlled by four factors: (1) suboxic diagenesis; (2) oxic diagenesis; (3) hydrogenous precipitation; and (4) hydrothermal precipitation. The first three are identical to those identified in studies of nodules from the North Pacific; the fourth factor represents the first quantitative determination of a significant hydrothermal end-member in ferromanganese nodules. Nodules apparently acquire a hydrothermal component through the accretion of colloidal-sized hydrothermal precipitates which are widely dispersed from their origin at vents along the East Pacific Rise (EPR). Nodules recovered from beneath the "shadow" of the present-day hydrothermal plumes emanating from the EPR contain significantly higher amounts of hydrothermal material relative to nodules from other areas.
\end{abstract}

\section{INTRODUCTION}

ONE OF THE EARLIEST disputes in marine geochemistry concerned the primary source of chemical elements present in ferromanganese nodules. The first such nodules to be studied in detail were those recovered during the voyage of the HMS Challenger (1873-1876), described by MURRAY and RENARD (1891). Analyses of these nodules showed they were essentially concretionary oxides of iron and manganese which generally contained high concentrations of certain trace elements and sometimes included minor amounts of silicate and biogenous material. While it appeared that seawater was the immediate source of the elements present in the nodules, MURRAY and RENARD (1891) disagreed concerning the primary source of these elements. Murray suggested the elements in the nodules were derived mainly from volcanic materials and were introduced into seawater through the submarine weathering of basalts, while Renard argued that the nodules acquired their constituent elements primarily from continental runoff and precipitation from normal seawater (MURRAY and RENARD, 1891, as summarized in CRONAN, 1980).

We now recognize that this controversy was based on a false premise, i.e., the idea that a single predominant source is responsible for nodule compositions. Numerous studies subsequently have shown that ferromanganese nodules actually accrue elements from a variety of sources, including volcanic, hydrogenous, continental (ARRHENIUS et al., 1964; CRONAN, 1967) and even cosmic sources (PETTERSSON, 1959), as well as by diagenetic remobilization of metals from the underlying sediments (LYNN and BONATTI, 1965). Hence, the focus of recent inquiry has shifted, such that the problem is no longer to identify a single source for the elements in nodules but rather to distinguish between nodules containing elements from a variety of sources.

The objective of the present study is to identify and quantify the presence of a hydrothermal component in deep-sea ferromanganese nodules. The possibility of hydrothermal con-

* Present address: EMCON Associates, Glendale, CA, U.S.A.

** Author to whom correspondence should be addressed. tributions to nodule compositions was recognized by BONATTI et al. (1972), who included hydrothermal sources as a potential end-member in their qualitative classification scheme of ferromanganese oxide compositions. Yet, until recently, there was little reason to believe that hydrothermal contributions were significant in a quantitative sense. For example, given the oxidizing conditions that commonly prevail in the deep sea, much of the iron and manganese from hydrothermal sources might be expected either to precipitate close to the point of discharge on the sea floor or else to become fractionated from each other over relatively short distances. Thus, buth the compositional integrity and areal extent of any hydrothermal "signal" were considered rather limited, other than possibly contributing to the overall manganese content of seawater (LYLE, 1976).

Several recent discoveries serve as a basis for challenging this viewpoint. Sea-floor hydrothermal activity is now recognized as a pervasive marine process, involving substantial fluxes of several elements relative to their fluvial inputs (EDMOND et al., 1982). Measurements of the ${ }^{3} \mathrm{He}$ anomaly in seawater (LUPTON and CRAIG, 1981) and the geochemistry of metalliferous sediments in the southeastern Pacific Ocean (DYMOND, 1981; HEATH and DYMOND, 1981) have confirmed that hydrothermal effluents are dispersed over distances of a few thousand $\mathrm{km}$ east and west of their sources along the East Pacific Rise (EPR). Moreover, detailed geochemical analyses of both surficial sediments (DYMOND, 1981) and DSDP sediment cores (RUHLIN and OWEN, 1986) have shown that, rather than being fractionated, the iron and manganese content of dispersed hydrothermal precipitates remains highly stable: so stable, in fact, that the $\mathrm{Mn} / \mathrm{Fe}$ ratio (as well as those of other elements) can serve as a characteristic signal to distinguish the presence of hydrothermally derived material from that of other sources in sediments of widely varying composition (DYMOND, 1981). These observations suggest the hypothesis that the composition of ferromanganese nodules, especially those found beneath the "shadow" of hydrothermal plumes, may contain a significant hydrothermal component. We have examined this hypothesis by conducting various statistical analyses on published data representing nodules recovered from the southeast Pacific Ocean. 


\section{METHODS}

\section{Experimental design}

The geochemical data for the 76 ferromanganese nodule samples examined in this study (Table 1) were obtained by screening the entire ferromanganese nodule data inventory of the National Geophysical Data Center in Boulder, Colorado, U.S.A. The NGDC inventory consists of information compiled from 544 sources on thousands of ferromanganese nodule samples, including extensive data sets provided by academic institutions and government agencies in France, Germany, Japan, the Soviet Union and the United States. Most of the nodule samples included in this study were recovered

\begin{tabular}{|c|c|c|c|c|c|c|c|c|}
\hline \multicolumn{2}{|c|}{ Sample ${ }^{1}$} & \multicolumn{2}{|c|}{ Postition } & \multicolumn{5}{|c|}{ Composition (wt i) } \\
\hline No. & Iden. Code & Lat.('S) & Long. ( $\mathrm{W})$ & Mn & $\mathrm{Fe}$ & Co & $N_{1}$ & $\mathrm{Cu}$ \\
\hline 1 & 26600180 & 13.423 & 134.158 & 10.2 & 15.3 & 0.37 & 0.79 & 0.41 \\
\hline 2 & 26600240 & 10.633 & 134.867 & 7.00 & 10.8 & 0.03 & 0.29 & 0.22 \\
\hline 3 & 26600280 & 12.850 & 135.217 & 31.0 & 9.10 & 0.11 & 9.90 & 1.20 \\
\hline 4 & 26600281 & 12.850 & 135.217 & 23.9 & 7.00 & 0.09 & 1.46 & 0.92 \\
\hline 5 & 26600300 & 13.617 & 135.517 & 23.8 & 11.65 & 0.12 & 1.8 & 0.91 \\
\hline 6 & 26600310 & 14.983 & 136.033 & 12.0 & 9.80 & 0.12 & 0.77 & 0.53 \\
\hline 7 & 26600311 & 14.983 & 136.033 & 15.2 & 14.7 & 0.14 & 0.90 & 0.44 \\
\hline 8 & 26600360 & 12.317 & 136.950 & 9.00 & 10.9 & 0.10 & 0.36 & 0.16 \\
\hline 9 & 26600320 & 15.383 & 136.300 & 23.6 & 9.82 & 0.12 & 1.22 & 0.50 \\
\hline 10 & 26600322 & 15.383 & 136.300 & 20.3 & 8.10 & 022 & 2,17 & 1.07 \\
\hline 11 & 26600323 & 15.383 & 136.300 & 19.6 & 18.2 & 0.14 & 1.00 & 0.64 \\
\hline 12 & 26600380 & 18.967 & 137.600 & 16.8 & 19.6 & 0.23 & 0.23 & 0.22 \\
\hline 13 & 26600381 & 18.967 & 137.600 & 2.88 & 10.5 & 004 & 009 & 0.12 \\
\hline 14 & 26700230 & 17.600 & 141.917 & 22.8 & 231 & 070 & 0.48 & 0.23 \\
\hline is & 26700231 & 17.600 & 141.917 & 16.0 & 16.2 & 0.49 & 0.34 & 0.09 \\
\hline 16 & 23100040 & 23.783 & 140.433 & 6.00 & 10.0 & 0.04 & 040 & 0.10 \\
\hline 17 & 26100310 & 13.533 & 89.083 & 23.6 & 10.8 & 0.10 & 1.83 & 0.46 \\
\hline 18 & 26100311 & 13.535 & 89.083 & 21.3 & 10.5 & 013 & 0.94 & 0.41 \\
\hline 19 & $261003 / 1$ & 11.233 & 89.583 & 25.1 & 8.88 & 0.13 & 1.11 & 0.78 \\
\hline 20 & 26100342 & 11.233 & 89.583 & 29.1 & 11.9 & 0.11 & 1.50 & 0.72 \\
\hline 21 & 26100343 & 11.233 & 89.583 & 31.0 & 10.5 & 0.11 & 1.20 & 0.67 \\
\hline 22 & 26100344 & 11.233 & 89.583 & 41.7 & 8.40 & 0.07 & 1.50 & 0.72 \\
\hline 23 & 26100441 & 11.083 & 82.517 & 37.7 & 4.76 & 0.05 & 1.32 & 083 \\
\hline 24 & 26100460 & 12.417 & 85.262 & 29.0 & 7.36 & 0.04 & 1.17 & 0.92 \\
\hline 25 & 26100480 & 12.483 & 87.897 & 23.9 & 7.42 & 0.11 & 1.50 & 0.87 \\
\hline 26 & 26200040 & 10.617 & 91.317 & 0.32 & 1.36 & 0.02 & 0.01 & 0.01 \\
\hline 27 & 26300331 & 10.633 & 109.600 & 38.7 & 5.50 & 0.03 & 0.45 & 0.83 \\
\hline 28 & 26300510 & 12.543 & 101683 & 35.1 & 3.27 & 0.04 & 8.95 & 0.52 \\
\hline 29 & 26300520 & 12.253 & 104.228 & 26.7 & 7.63 & 0.05 & 1.35 & 0.88 \\
\hline 30 & 26300770 & 13.683 & 102.133 & 28.8 & 12.7 & 0.12 & 1.52 & 0.60 \\
\hline 31 & 26300771 & 13.683 & 102.133 & 30.9 & 10.0 & 0.11 & 1.74 & 0.69 \\
\hline 32 & 26100330 & 18.785 & 89433 & 26.6 & 8.80 & 0.24 & 1.26 & 0.76 \\
\hline 33 & 26100331 & 18.785 & 89.433 & 47.3 & 9.59 & 0.12 & 1.72 & 0.71 \\
\hline 34 & 26100332 & 18.785 & 89.433 & 27.8 & 12.6 & 0.18 & 1.70 & 0.90 \\
\hline 35 & 26100470 & 17.467 & 86.700 & 232 & 9.46 & 0.08 & 1.20 & 0.70 \\
\hline 36 & 26300091 & 19.192 & 102.400 & 21.5 & 13.3 & 0.20 & 1.90 & 0.74 \\
\hline 37 & 26300093 & 19.192 & 102.400 & 17.2 & 11.6 & 0.16 & 1.52 & 0.59 \\
\hline 38 & 22600070 & 21.603 & 94.933 & 15.5 & 10.6 & 018 & 1.09 & 0.62 \\
\hline 39 & 22600071 & 21.603 & 94.933 & 18.8 & 11.5 & 014 & 0.66 & 0.24 \\
\hline 40 & 23100110 & 29.150 & 143.017 & 17.7 & 21.7 & 0.36 & 0.46 & 0.22 \\
\hline 41 & 23100111 & 29.150 & 143.017 & 12.7 & 15.5 & 0.26 & 0.33 & 0.16 \\
\hline 42 & 19400135 & 32.600 & 137.717 & 16.6 & 10.0 & 0.22 & 0.77 & 0.30 \\
\hline 43 & 19400161 & 34.017 & 138.917 & 19.6 & 21.7 & 0.45 & 0.50 & 0.21 \\
\hline 44 & 19400010 & 39.633 & 130.217 & 22.7 & 11.8 & 0.30 & 1.13 & 0.40 \\
\hline 45 & 19400020 & 39.683 & 131.383 & 20.7 & 12.0 & 0.31 & 0.82 & 0.41 \\
\hline 46 & 19400021 & 39.683 & $131 \quad 383$ & 16.60 & 10.4 & 0.18 & 0.82 & 0.30 \\
\hline 47 & 19400090 & 35.183 & 135.533 & 19.6 & 14.2 & 0.73 & 0.33 & 0.05 \\
\hline 48 & 19400100 & 37.083 & 137.000 & 18.9 & $11 ?$ & 038 & 0.91 & 043 \\
\hline 49 & 19400101 & 37.083 & 137.000 & 20.2 & 12.6 & 0.16 & 0.82 & 0.35 \\
\hline so & 19400102 & 37.083 & 137.000 & 26.5 & 11.2 & 0.28 & 1.50 & 066 \\
\hline$s 1$ & 19400103 & 37.083 & 137.000 & 24.6 & 15.4 & 033 & 0.90 & $\begin{array}{l}053 \\
053\end{array}$ \\
\hline 52 & 19400110 & 36.383 & 137.250 & 18.7 & 13.0 & 0.38 & 0.69 & 0.33 \\
\hline 53 & 19400111 & 36.383 & 137.250 & 16.8 & 13.1 & 0.43 & 0.97 & 0.35 \\
\hline 54 & 19400120 & 36.550 & 137.400 & 14.1 & 12.4 & 0.36 & 0.64 & 029 \\
\hline 55 & 19400121 & 36.550 & 137.400 & 18.1 & 10.5 & 0.34 & $\begin{array}{l}0.10 \\
1.10\end{array}$ & 0.50 \\
\hline 56 & 19400170 & 35.075 & 138.662 & 17.5 & 15.8 & 0.43 & 0.39 & 0.11 \\
\hline 57 & 19400171 & 35.075 & 138.662 & 19.0 & 15.8 & 0.42 & 0.50 & 018 \\
\hline 58 & 19400172 & 35075 & 138.662 & 16.0 & 14.3 & 0.32 & 0.42 & 015 \\
\hline 59 & 22500070 & 25.517 & 85.233 & 42.3 & 2.47 & 0.17 & 0.26 & 015 \\
\hline 60 & 22500071 & 25.517 & 85.233 & 37.3 & 11.2 & 0.70 & 0.56 & 0.16 \\
\hline 61 & 22500076 & 25517 & 85.233 & 28.8 & 9.11 & 0.10 & 0.32 & 0.12 \\
\hline 62 & 18900072 & 33.050 & 82.050 & 17.0 & 13.1 & 0.11 & 0.80 & 040 \\
\hline 63 & 18900073 & 33.050 & 82.050 & 16.7 & 13.8 & 0.09 & 0.62 & 037 \\
\hline 64 & 18900140 & 33.000 & 85.900 & 20.6 & 11.2 & 0.12 & 1.21 & 051 \\
\hline 65 & 18900200 & 32.217 & 89.450 & 26.8 & 19.9 & 0.16 & 0.58 & 019 \\
\hline 66 & 18900220 & 33.075 & 89.550 & 22.2 & 11.2 & 0.10 & 1.31 & $\begin{array}{l}113 \\
057\end{array}$ \\
\hline 67 & 18900230 & 33033 & 84.050 & 15.5 & 15.9 & 0.14 & 0.50 & 0.34 \\
\hline 68 & 18900040 & 37.067 & 81.833 & 26.5 & 980 & 0.11 & 1.60 & 0.72 \\
\hline 69 & 18900080 & 39.950 & 82.950 & 23.3 & 11.4 & 0.13 & 1.21 & 0.47 \\
\hline 70 & 18900081 & 39.950 & 82.950 & 22.3 & 11.9 & 0.12 & 1.01 & 0.45 \\
\hline 71 & 18900090 & 37.483 & 83.117 & 17.2 & 12.7 & 0.12 & 0.78 & 0.45 \\
\hline 72 & 18900091 & 37.483 & 83.117 & 18.5 & 12.3 & 0.08 & 0.69 & 0.34 \\
\hline 73 & 18900092 & 37.483 & 83.117 & 15.4 & 13.4 & 0.16 & 080 & 0.73 \\
\hline 74 & 18900093 & 37.483 & 83.117 & 16.3 & 15.0 & 0.16 & 0.58 & 019 \\
\hline 75 & 19000020 & 35.733 & 92.700 & 14.1 & 24.7 & 0.10 & 0.49 & 0.21 \\
\hline 76 & 19000071 & 39.850 & 96.867 & 21.3 & 11.8 & 0.07 & 1.13 & 0.43 \\
\hline
\end{tabular}

Sample Nos, were assigned for this study; Sample Nos. 1.16 are from the NW quadrant: Sample No.s 17-39 from the NE quadrant: Sample Nos. 40-58 from the SW quadrant; and Sample Nos. $59-76$ from the $S E$ quadrant (see
Fig. 1). Sample Iden. Code numbers are equivalent to NGDC codes.

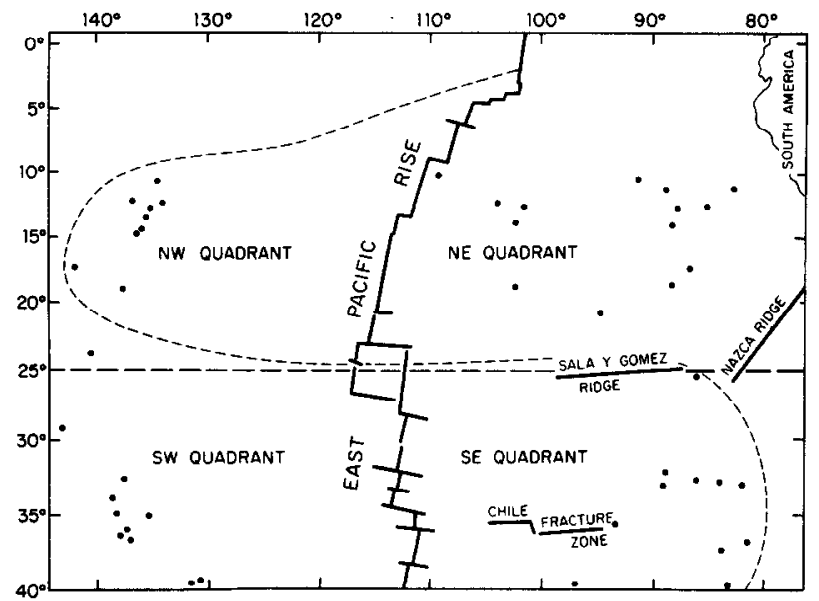

FIG. 1. Map shows locations of nodule samples (black dots) analyzed in this study and dispersal pattern (shorter dashed curves) of hydrothermal effluents (after EDMOND et al., 1982). Quadrants are defined by the EPR (east-west boundary) and an imaginary line (longer dashed line) along $25^{\circ} \mathrm{S}$ latitude. Note that samples from the NW and SE quadrants lie beneath the "shadow" of hydrothermal plumes, while those in the NE and SW quadrants do not.

during research cruises conducted by the Scripps Institution of Oceanography, Oregon State University, Lamont-Doherty Geological Observatory, Florida State University and Akademiia Nauk (USSR), and were analyzed by investigators from these institutions. In some instances the original geochemical data from these sources were reported to more than the three significant figures shown in Table 1. We have rounded off all original data to three significant figures for the sake of consistency of this investigation.

These 76 nodule samples were collected from a broad, rectangular area of the South Pacific Ocean, ranging from latitude $10^{\circ} \mathrm{S}$ to $40^{\circ} \mathrm{S}$ and longitude $80^{\circ} \mathrm{W}$ to $145^{\circ} \mathrm{W}$ (Fig. 1). All nodule samples from within this area for which bulk geochemical data for the concentrations of $\mathrm{Mn}, \mathrm{Fe}, \mathrm{Co}, \mathrm{Ni}$ and $\mathrm{Cu}$ were reported are included in this study. The outer dimensions of this area, as well as the subdivisions defined in this study (see discussion below), are based on the extant mid-depth circulation pattern and its effect on the distribution of hydrothermal precipitates as described by EDMOND et al. (1982). These authors note that, due to the markedly asymmetric mid-depth circulation pattern along this portion of the EPR, hydrothermal effluents emanating from the ridge axis are distributed laterally for thousands of $\mathrm{km}$ in either an easterly or westerly direction. Flow is predominantly to the east in the southern portion of the study area and to the west in the northern portion (Fig. 1). Relative to the EPR, this pattern results in a pronounced eastern lobe in the distribution of hydrothermal precipitates, centered at about 30 to $35^{\circ} \mathrm{S}$ (DYMOND, 1981 ), and a western lobe centered at about 15 to $20^{\circ} \mathrm{S}$ (HOFFERT et al., 1979). The inflection point between these two lobes lies along $25^{\circ} \mathrm{S}$ (EDMOND et al., 1982).

The asymmetric distribution of hydrothermal precipitates in this region is fortuitous, inasmuch as it allows us to redefine the study area in terms of a classic block design (e.g., HENLY, 1981) for the purposes of testing various statistical hypotheses. Consequently, we have subdivided the study area into four "quadrants", with the crest of the EPR serving as the east-west boundary and an imaginary line along $25^{\circ} \mathrm{S}$ (the latitude of current inflection) as the north-south boundary (Fig. 1). Because they enclose the lobes of present-day hydrothermal effluent distribution, the northwest and southeast quadrants are designated here as the "hydrothermal" quadrants, while the northeast and southwest quadrants are referred to as the "background" quadrants. Our objective is to quantify the amount of hydrothermal material in all of the nodules included in this study using an endmember composition factor analysis technique (see discussion below). If hydrothermal emanations from the EPR are incorporated into ferromanganese nodules to an appreciable extent, then the composition of nodules from the "hydrothermal" quadrants should contain 
a significantly greater amount of hydrothermal material than those nodules recovered from the "background" quadrants. This hypothesis assumes that the existing mid-depth circulation pattern has been extant over a sufficient time-span to affect nodule compositions. Our statistical tests should provide insight concerning the validity of this assumption.

The four-quadrant experimental design also allows us to control other factors which might otherwise introduce uncertainty into our results. The two factors of greatest concern here are the possible influence of (1) biogenous inputs from the highly productive equatorial region north of the study area and (2) terrigenous inputs from the South American land mass east of the study area. Each of these factors has been evaluated through paired comparisons of compositional data from the nodules in each of the four quadrants.

\section{Statistical methods}

Until recently, geochemists have had limited success in their attempts to determine the composition of end-members in various geologic mixtures using Q-mode factor analysis. The major difficulty has been that transformations of the original data during the analysis often produced negative factor scores for some variables, implying that negative "concentrations" of these variables existed in the endmembers that were identified. LEINEN and PISIAS (1984) recently have developed a modified version of standard Q-mode factor analysis and have demonstrated quite conclusively that their technique effectively eliminates this problem. The key mathematical modification involves the use of a nonorthogonal rotation of end-member vectors toward the mean vector to bring each of the end-members into positive vector space. In geochemical terms, the Leinen and Pisias method is capable of generating accurate and objective estimates of the endmember compositions of geologic mixtures. We have used this technique to determine both the number and the chemical composition of the significant geochemical end-members which comprise the bulk composition of the nodule samples. The relative amounts of each of these compositional end-members present in each sample were then determined using a normative analysis technique based on linear programming (e.g., OWEN, 1980; DYMOND, 1981; HEATH and DYMOND, 1981; DYMOND et al., 1984). Finally, we have used the Wilcoxon two-sample test to determine if the relative amounts of a particular compositional end-member (e.g., the hydrothermal component) in the nodules from two different quadrants are csscntially the same or significantly different (at the $p<0.05$ level). This is a nonparametric method, analogous to the more commonly known Students " $t$ " test: its use is preferred here because it is not based on the assumption that the statistical samples being compared are derived from populations that are normally distributed (ALDER and ROESSLER, 1977).

\section{RESULTS AND DISCUSSION}

\section{Identification of the hydrothermal component}

The Q-mode factor analysis of the 76 nodule samples revealed that four factors or end-members account for $99.2 \%$

\begin{tabular}{|c|c|c|c|c|}
\hline & Factor 1 & Factor 2 & Factor 3 & Factor 4 \\
\hline $\operatorname{Mn}(8)$ & 413 & 23.0 & 10.9 & 42.2 \\
\hline $\mathrm{Fe}$ & 1.23 & 220 & 35.3 & 4.58 \\
\hline co & 0.00 & 1.35 & 0.00 & 0.05 \\
\hline $\mathrm{Ni}$ & 2.80 & 057 & 043 & 0.00 \\
\hline $\mathrm{Ca}$ & 1.53 & 000 & 022 & 0.00 \\
\hline Variance & 49.3 & 33.1 & 14.1 & 2.78 \\
\hline \& Cum. Variance & 49.3 & 82.4 & 96.5 & 99.3 \\
\hline
\end{tabular}

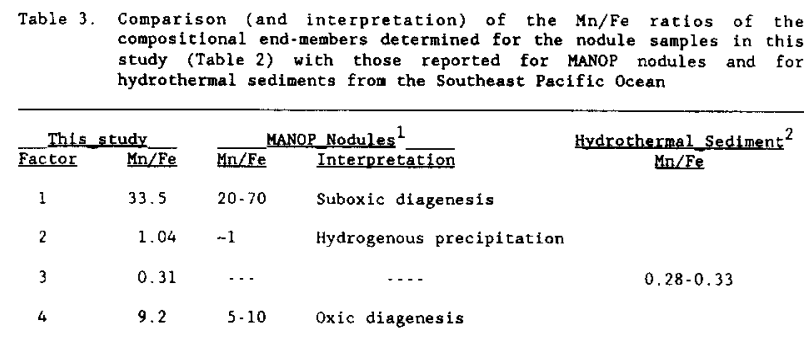

\begin{tabular}{|c|c|c|c|c|}
\hline \multicolumn{2}{|c|}{ This_study } & \multicolumn{2}{|c|}{ MANOP Nodules ${ }^{1}$} & \multirow{2}{*}{$\frac{\text { Bydrochermal sediment }}{2}$} \\
\hline Factor & m/Fe & $\mathrm{Mn} / \mathrm{Fe}$ & Interpretation & \\
\hline 1 & 33.5 & $20-70$ & Subaxic diagenesis & \\
\hline 2 & 1.04 & -1 & Hydrogenous precipitation & \\
\hline 3 & 0.31 & $\cdots$ & $\cdots$ & $0.28-0.33$ \\
\hline 4 & 9.2 & 5.10 & Oxic diagenesis & \\
\hline
\end{tabular}

1. From Dymond ex al (1984).
2 From Dymond and Eklund (1978), Dymond (1981) and Ruhlin and Owen (1986)

of the total variance in the data set. The scaled varimax factor scores for all five variables ( $\mathrm{Mn}, \mathrm{Fe}, \mathrm{Co}, \mathrm{Ni}$ and $\mathrm{Cu}$ ) were converted to compositional end-members by extending the factor analysis using MIESCH's (1976) technique of data closure by summing the elemental concentrations to a constant value (see discussion below) and then applying the vector rotation technique of LEINEN and PISIAS (1984). The results of this procedure, i.e., our calculated values for the composition of each of the four end-members in the factor analysis, are summarized in Table 2.

DYMOND et al. (1984) investigated the composition of ferromanganese nodules from Manganese Nodule Project (MANOP) sites H, S and R (see Fig. 1 of their study) in the northeastern equatorial Pacific Ocean. Several aspects of their study are relevant to the present investigation, particularly inasmuch as their results greatly facilitated the interpretation of the factor analysis reported here. For example, they found that the composition of the MANOP samples could be accounted for by variable contributions from three accretionary processes: (1) hydrogenous precipitation, i.e., direct precipitation or accumulation of colloidal metal oxides from seawater; (2) oxic diagenesis which involves various reactions in oxidized sediments that add transition metals to nodules; and (3) suboxic diagenesis, i.e., nodule accretion by the diagenetic remobilization of manganese within the sediments. The concentrations of these three end-members in an "average" whole nodule are $1.50,57.8$ and $40.7 \%$, respectively. By multiplying each of these values by the weight percentage of $\mathrm{Mn}, \mathrm{Fe}, \mathrm{Co}, \mathrm{Ni}$ and $\mathrm{Cu}$ in each end-member (given in Table 6 of their study), we estimate that the sum of these five elements in an average nodule is $46.9 \%$, and we have used this figure to close our data set to a constant sum. However, we emphasize that any comparisons between the predicted composition of the end-members generated in this study and those reported by DYMOND et al. (1984) will be done on the basis of inter-element ratios within the end-members, rather than the absolute value of various elements within the endmembers. The inter-element ratios of the data reported in Table 2 would remain the same no matter what value was chosen for a constant sum. Consequently, our estimate of $46.9 \%$ is simply a first approximation of the sum of the five elements in an "average" nodule and will in no way affect the validity of any comparisons that are made.

Since $\mathrm{Mn}$ and $\mathrm{Fe}$ are the two major constituents of ferromanganese nodules, the $\mathrm{Mn} / \mathrm{Fe}$ ratio served as the primary basis for interpreting the Q-mode factor analysis. The Mn/ Fe ratios (Table 3 ) of three of the four factors determined 
here fall within the range of values reported for the three endmembers of nodule compositions by DYMOND et al. (1984). Thus, we suggest that our factors 1,2 and 4 are analogous to the suboxic diagenesis, hydrogenous precipitation and oxic diagenesis end-members, respectively, determined for nodules collected from the MANOP sites.

Factor 3 is the most intriguing result of the factor analysis in the present study. This factor accounts for $14.1 \%$ of the total variance in the data set and is dominated by $\mathrm{Fe}$ and $\mathrm{Mn}$. It is the only factor in which $\mathrm{Mn} / \mathrm{Fe}<1$ and the only one that does not obviously correspond to any of the three end-members of nodule composition determined by DYMOND et al. (1984). The existence of this factor indicates the presence of an additional compositional end-member in our samples, which either was not present or did not play a major role in influencing the composition of the nodules from MANOP sites $\mathrm{H}, \mathrm{S}$ and $\mathrm{R}$.

Several investigations (DYMOND and EKLUND, 1978; DYMOND, 1981; GRAYBEAL and HEATH, 1984; RUHLIN and OWEN, 1986) have demonstrated that the presence of a hydrothermal component in a sedimentary mixture can be readily identified and distinguished from materials from other sources on the basis of highly characteristic ratios (particularly $\mathrm{Mn} / \mathrm{Fe} \sim 0.3$ ) among various elements which are representative of a pure hydrothermal end-member. The $\mathrm{Mn} / \mathrm{Fe}$ ratio of factor 3 falls within the range of values typically observed for hydrothermal sediments (Table 3). Other inter-element ratios (e.g., $\mathrm{Cu}, \mathrm{Fe}, \mathrm{Co} / \mathrm{Fe}, \mathrm{Ni} / \mathrm{Fe}$ ) calculated for factor 3 also strongly agreed with their hydrothermal analogs. Based on this comparison, we interpret factor 3 to represent a hydrothermal end-member and conclude that the nodules in this study contain a significant amount of material derived from hydrothermal activity along the EPR.

\section{Distribution of the hydrothermal component}

A quantitative estimate of the relative amount of each compositional end-member present in each nodule sample (Table 4) was determined using a normative analysis model. The model assumes the bulk composition of any nodule sample can be accounted for by some linear combination of contributions from each end-member. Optimum solutions for each nodule sample were determined by linear programming. An assessment of the viability of the model is obtained from an examination of the coefficients of determination for the individual elements (i.e., the proportion of the total variance in each parameter, which is explained by the normative analysis model). The coefficients of determination were as follows: $\mathrm{Mn}=100 \% ; \mathrm{Fe}=99.8 \% ; \mathrm{Ni}=95.4 \% ; \mathrm{Co}=84.4 \%$; $\mathrm{Cu}=75.2 \%$. These values indicate $\mathrm{Mn}, \mathrm{Fe}$ and $\mathrm{Ni}$ maintain a very high degree of compositional integrity and consistent geochemical behavior within each end-member, while there is probably some degree of breakdown in the constant composition assumption for $\mathrm{Co}$ and $\mathrm{Cu}$.

The model predicts that all but two (nos. 59 and 60) of the 76 samples contain some amount of hydrothermal material (Table 4). We note that these two exceptional samples were collected at a water depth of $920 \mathrm{~m}$, which is more than $1200 \mathrm{~m}$ shallower than the recovery depth of any of the other samples and well above the depth $(\sim 3.0 \mathrm{~km})$ at which hy-

\begin{tabular}{|c|c|c|c|c|}
\hline Sample & $\begin{array}{c}\text { Factor } 1 \\
\text { (suboxic diagenesis) }\end{array}$ & $\begin{array}{c}\text { Factor 2 } \\
\text { (Hydrogenous) }\end{array}$ & $\begin{array}{l}\text { Factor } 3 \\
\text { (Hydrotherma1) }\end{array}$ & $\begin{array}{c}\text { Factor } 4 \\
\text { (oxic diagenesis) }\end{array}$ \\
\hline 1 & 237 & 0 & 76.3 & 0 \\
\hline 2 & 14.1 & 5.47 & 73.8 & 6.67 \\
\hline 3 & 68.8 & 8.79 & 19.8 & 262 \\
\hline 4 & 68.5 & 9.33 & 19.4 & 272 \\
\hline 5 & 61.2 & 0 & 38.8 & 0 \\
\hline 6 & 44.8 & 0 & 55.2 & 0 \\
\hline 7 & 35.1 & 9.78 & 55.1 & 0 \\
\hline 8 & 16.9 & 16.7 & 58.5 & 7.90 \\
\hline 9 & 51.2 & 114 & 26.5 & 10.9 \\
\hline 10 & 50.0 & 13.6 & 24.5 & 3.91 \\
\hline 11 & 31.9 & 12.2 & 52.1 & 3.86 \\
\hline 12 & 0 & 20.7 & $5 / 1.2$ & 251 \\
\hline 13 & 0 & 0 & 100 & 0 \\
\hline 14 & 1.78 & 51.1 & 31.0 & 16.1 \\
\hline 15 & 1.96 & 51.0 & 31.1 & 16.0 \\
\hline 16 & 168 & 8.45 & 74.7 & 0 \\
\hline 17 & 593 & 9.49 & 312 & 0 \\
\hline 18 & 39.8 & 12.9 & 301 & 17.1 \\
\hline 19 & 46.1 & 11.9 & 21.2 & 20.8 \\
\hline 20 & 518 & 8.38 & 278 & 12.0 \\
\hline 21 & 11.2 & 7.75 & 22.1 & 29.0 \\
\hline 22 & 45.2 & 3.20 & 12.6 & 390 \\
\hline 23 & 482 & 2. 28 & 5.36 & 44.1 \\
\hline 24 & 478 & 248 & 183 & 31.4 \\
\hline 25 & 689 & 113 & 19.7 & 010 \\
\hline 26 & 0 & 0 & 100 & 0 \\
\hline 27 & 159 & 0 & 548 & 78.6 \\
\hline 28 & 39.3 & 1.34 & 1.11 & 582 \\
\hline 29 & 57.9 & 4.14 & 21.0 & 171 \\
\hline 30 & 51.4 & 915 & 396 & 986 \\
\hline 31 & 61.5 & 8.47 & 21.9 & 813 \\
\hline 32 & 495 & 21.7 & 14.0 & 148 \\
\hline 33 & 453 & 5.61 & 11.4 & 377 \\
\hline 34 & 590 & 114 & 29.7 & 0 \\
\hline 35 & 521 & 761 & 282 & 12.1 \\
\hline 36 & 54.0 & 0 & 460 & 0 \\
\hline 37 & 51.2 & 0 & 488 & 0 \\
\hline 38 & 50.7 & 0 & 493 & 0 \\
\hline 39 & 26.6 & 147 & 355 & 23.2 \\
\hline 40 & 506 & 30.5 & 50.4 & 141 \\
\hline 41 & 5.10 & 30.8 & 50.0 & 141 \\
\hline 42 & 36.0 & 27.0 & 28.4 & 867 \\
\hline 43 & 5.63 & 364 & 43.2 & 148 \\
\hline 44 & 42.4 & 28.4 & 23.0 & 6.20 \\
\hline 45 & 30.0 & 310 & 24.3 & 14.7 \\
\hline 46 & 38.8 & 21.8 & 32.6 & 6.73 \\
\hline 47 & 0.10 & 72.3 & 6.21 & 21.4 \\
\hline 48 & 364 & 41.5 & 193 & 286 \\
\hline 49 & 31.4 & 15.7 & 35.9 & 17.1 \\
\hline 50 & 54.3 & 24.2 & 19.8 & 173 \\
\hline 51 & 26.1 & 26.9 & 29.1 & 17.8 \\
\hline 52 & 229 & 39.6 & 252 & 12.4 \\
\hline 53 & 30.0 & 416 & 28.4 & 0 \\
\hline 54 & 24.7 & 448 & 30.6 & 0 \\
\hline 55 & 463 & 24.8 & 29.0 & 0 \\
\hline 56 & 5,40 & 43.0 & 317 & 19.9 \\
\hline 57 & 104 & 40.0 & 30.7 & 18.9 \\
\hline 58 & 977 & 35.0 & 36.3 & 19.0 \\
\hline 59 & 9.77 & 0 & 0 & 90.2 \\
\hline 60 & 11.3 & 36.4 & 0 & 52.3 \\
\hline 61 & 969 & 6.64 & 18.5 & 65.2 \\
\hline 62 & 33.1 & 11.8 & 45.6 & 9.41 \\
\hline 63 & 23.4 & 9.27 & 49.2 & 18.1 \\
\hline 64 & 52.1 & 12.3 & 34.4 & 1.18 \\
\hline 65 & 11.4 & 10.4 & 44.1 & 34.1 \\
\hline 66 & 54.5 & 973 & 33.7 & 210 \\
\hline 67 & 14.7 & 145 & 53.7 & 17.2 \\
\hline 68 & 63.3 & 9.77 & 24.9 & 2.34 \\
\hline 69 & 47.9 & 12.0 & 31.0 & 9.11 \\
\hline 70 & 396 & 11.1 & 33.8 & 15.5 \\
\hline 71 & 32.5 & 13.0 & 434 & 11.2 \\
\hline 72 & 279 & 7.91 & 426 & 21.6 \\
\hline 73 & 334 & 18.4 & 463 & 1.82 \\
\hline 74 & 191 & 16.7 & 487 & 15.5 \\
\hline 75 & 7.2 & 8.49 & 76.2 & 807 \\
\hline 16 & $46 y$ & 6.67 & 38.0 & 840 \\
\hline
\end{tabular}

drothermal effluents are emitted from the EPR in the study area (EDMOND et al., 1982). In all other cases our results indicate the areal distribution of the hydrothermal endmember is not limited to those samples recovered from locations within the confines of the present-day distribution pattern of hydrothermal effluents (Fig. 1). On the other hand, inspection of the values associated with the hydrothermal end-member (factor 3 ) in Table 4 does suggest that samples from the postulated "hydrothermal" quadrants (NW and SE) contain significantly greater amounts of hydrothermal material than their counterparts in the "background" (NE and SW) quadrants. This hypothesis was tested by a statistical comparison (Wilcoxon test), for all possible pairings of the four quadrants, of the mean value of the amount of hydro- 
thermal component present in the nodules from each quadrant. The results of these tests (in which the 0.05 significance level was used as the criterion for "significant difference") were as follows:

1) Nodule samples from both of the postulated "hydrothermal" quadrants contain significantly greater amounts of the hydrothermal end-member than either of the "background" quadrants.

2) No significant difference exists between the amount of hydrothermal material in nodules from the two "hydrothermal" quadrants.

3) No significant difference cxists between the amount of hydrothermal material in nodules from the two "background" quadrants.

The four-quadrant experimental design allows us to evaluate another important aspect of the data. Since the normative analysis model assumes the bulk composition of a nodule sample is essentially the sum of the contributions from the four compositional end-members, any process which tends to increase or decrease the contribution of one endmember will have the opposite effect on all the other endmembers. For example, it is conceivable that the relatively high amounts of hydrothermal material in the nodules from the NW and SE quadrants may not be directly due to an enhanced distribution of hydrothermal material in these quadrants, but instead could simply be a reflection of some process which tends to diminish the hydrothermal contribution in the NE and SW quadrants in favor of some other end-member. This type of indirect influence most likely would occur because of processes which favor the suboxic diagenesis end-member (Factor 1) or the hydrogenous precipitation end-member (Factor 2), since each accounts for a greater percentage of the total variance in the data set than the hydrothermal end-member (Factor 3).

Two processes which might be significant in this regard are the influx of biogenous material from the highly productive equatorial zone north of the study area and the influx of terrigenous material from the South American landmass east of the study area. Any significant difference in biogenous inputs would probably be manifested as relatively higher amounts of dissolved trace elements in the overlying waters and greater amounts of organic matter reaching the sediments in the northern half of the study area. This, in turn, could increase the influence of the hydrogenous precipitation and suboxic diagenesis end-members in the nodule samples at the expense of the hydrothermal end-member. An analogous argument can be made for the influx of terrigenous material from the South American landmass, which would have a relatively greater effect on nodules in the two eastern quadrants.

Based on statistical comparison of all possible pairings of the four quadrants, neither of these two possible influences appears to have a discernable effect on the amount of the hydrothermal end-member present in the nodules. For example, any dilution effect due to biogenous and/or terrigenous inputs should be greatest in the NE quadrant, and least in the SW quadrant. Yet the statistical comparison indicates there is no significant difference in the amount of hydrothermal material in the nodules from these two quadrants.
From this, we infer that the higher amounts of the hydrothermal end-member determined for the nodule samples in the NW and SE quadrants are due primarily to the distribution of hydrothermal effluents by the mid-depth current regime and are not simply statistical artifacts resulting from variations in the other end-members.

\section{Accretion and variability of the hydrothermal component}

The relative importance of different sources of elements to nodules depends upon the proximity of the nodules to the sources, the transport and accretion mechanisms involved, and fluctuations in the intensity of the sources (CRONAN, 1980). The observed compositional differences between the four groups of nodules discussed here, as well as between these nodules and the MANOP nodules, are likely the result of variations in one or more of these parameters. For example, both the widespread dispersal and the remarkably constant composition of hydrothermal precipitates in the southeast Pacific suggest that nodules acquire hydrothermal materials through the accretion of colloidal-sized hydrothermal particles (DYMOND, 1984). Nodules which are situated both proximal to and directly beneath the dispersal pathway of plumes emanating from vents should be enriched in hydrothermal materials relative to nodules which are not.

The widespread dispersal of hydrothermal materials in the study area may also have an indirect influence on the relative mix of the oxic and suboxic diagenesis end-members in the nodule samples. The high $\mathrm{Mn} / \mathrm{Fe}$ ratios characteristic of these diagenetic end-members require a significant degree of $\mathrm{Fe}$ and $\mathrm{Mn}$ fractionation relative to the amounts present in the hydrothermal end-member (Table 3). Several authors (LYLE et al., 1977; CALVERT et al., 1978; HEN et al., 1979) have suggested this fractionation occurs as a result of the authigenic formation of Fe-rich smectite (e.g., nontronite), with the smectite serving as the Fe sink and nodules as the Mn sink. Colloidal Fe-Mn oxyhydroxides that form at spreading centers in hydrothermal fluids will undergo early diagenesis to form Fe-rich smectites whenever silica is available for chemisorption (HEATH and DYMOND, 1977; HEIN et al., 1979). The sources of silica in this case would include that released from the disolution opaline biogenic silica, which comprises 1 to $5 \%$ of the sediments in the study area (LISITZIN, 1972) on a carbonate-free, dry-weight basis, silica present in the hydrothermal effluents, and dissolved silica in water masses transported into the study area from the biologically productive regions lying to the south.

Although the factor analysis provides a quantitative ranking of the influence of each compositional end-member on the total variance in the data set, the physical significance of this ranking is meaningful only on a time-averaged basis. During any given time period, the relative influence of different sources may have been uniform or else may have varied due to non-steady-state processes. For example, in the case of the hydrothermal component, non-steady-state deposition could have resulted from a change in the current patterns which disperse hydrothermal effluents or possibly from pulsations in the intensity of hydrothermal activity in this region. At least four episodes of anomalously high (as much as 20 times Holocene levels) deposition of hydrothermal materials have been documented in the sediments from the EPR at $19^{\circ} \mathrm{S}$ 
between 25 and 29 My (LYLE et al., 1977). Data required to evaluate the temporal aspect of hydrothermal deposition, such as detailed compositional profiles through individual nodules, are not presently available. Consequently, whereas our analyses have highlighted spacial differences in the proportions of hydrothermal materials in the nodule samples, the question of whether or not the nodules record variations in the rate of hydrothermal deposition remains open.

\section{SUMMARY AND CONCLUSIONS}

Numerous investigations since the pioneering work of MURRAY and RENARD (1891) have shown that ferromanganese nodules accumulate elements from various sources, and that the bulk composition of the nodules can be accounted for by variable contributions from different accretionary processes. We have identified and quantified the presence of four distinct factors which control the composition of ferromanganese nodules from a broad area of the southeastern Pacific Ocean. These include (1) suboxic diagenesis, (2) hydrogenous precipitation, (3) hydrothermal precipitates and (4) oxic diagenesis. Three of these four factors are identical to those identified by DYMOND et al. (1984) in their study of nodules from MANOP sites in the North Pacific. This suggests that, except for the hydrothermal component, the same general processes are responsible for nodule compositions in both locations. The discovery of a significant hydrothermal end-member in the nodule samples examined in this study is also consistent with the evidence summarized by EDMOND et al. (1982) in support of both active hydrothermal venting and widespread dispersal of hydrothermal effluents away from the axis of the EPR in the southeast Pacific.

Three independent investigations of different sedimentary materials from the southeast Pacific, including Nazca Plate surficial sediments (DYMOND, 1981), sediments from DSDP site 598 (RUHLIN and OWEN, 1986) and the nodules in the present study, have each determined that the $\mathrm{Mn} / \mathrm{Fe}$ ratio of the hydrothermal component is remarkably constant at a value of $\sim 0.3$. Apparently, the major element ( $\mathrm{Fe}$ and $\mathrm{Mn}$ ) composition of the hydrothermal precipitates becomes fixed as they form and remains essentially constant during their dispersal as colloidal-sized particles and subsequent accretion by the nodules. The results of our analyses suggest that the nodule samples from the two quadrants (NW and SE) which underlie the present-day distribution pattern of hydrothermal effluents also contain significantly higher proportions of hydrothermal materials and, further, that the enrichment of the hydrothermal component in these samples cannot simply be attributed to variable contributions (e.g., dilution effects) involving the other compositional end-members.

Acknowledgements-The authors wish to thank Carla Moore of NGDC for providing the bulk nodule data and Nicklas Pisias for providing the computer programs used for factor analysis and linear programming. We are grateful to Douglas Ruhlin and Derwin Bell for their assistance in the computer programming and drafting aspects of this study, respectively, and to Bruce Wilkinson and Miriam Kastner for their comments and suggestions concerning this study. We wish to thank S. E. Calvert, G. R. Heath, D. Z. Piper and an anon- ymous reviewer for their comments and suggestions based upon a review of an earlier version of this paper. This research was supported by the Scott Turner Fund, the National Science Foundation under Grant number OCE-84 10034, and the Michigan Sea Grant Program, project number R/ER-17 under Grant number NA86AA-D-SGO43 from the Office of Sea Grant, National Oceanic and Atmospheric Administration (NOAA), U.S. Dept. of Commerce, and funds from the State of Michigan.

Editorial handling: S. E. Calvert

\section{REFERENCES}

ALDER H. L. and ROESSLER E. B. (1977) Introduction to Probability and Statistics, 6th edn. W. H. Freeman, San Francisco, 426p.

ARRHENIUS G., MERO J. and KORKISCH J. (1964) Origin of oceanic manganese materials. Science 144, 170-173.

BONATTI E., KRAEMER T. and RYDELL H. (1972) Classification and genesis of submarine iron-manganese deposits. In Ferromanganese Deposits on the Ocean Floor (ed. D. R. HORN), pp. 149-166. Natl. Sci. Foundation, Washington, D.C.

Calvert S. E., Price N. B., Heath G. R. and MoOre T. C., JR. (1978) Relationship between ferromanganese nodule compositions and sedimentation in a small survey area of the equatorial Pacific. J. Mar. Res. 36, 161-183.

CRONAN D. S. (1967) The geochemistry of some manganese nodules and associated pelagic deposits. Ph.D. thesis, Univ. of London.

CronaN D. S. (1980) Manganese nodules and encrustations. In Underwater Minerals. pp. 61-169. Academic Press, London.

DYMOND J. (1981) The geochemistry of Nazca Plate surface sediments: An evaluation of hydrothermal, biogenic, detrital and hydrogenous sources. In Nazca Plate: Crustal Formation and Andean Convergence (eds. L. D. KulM et al.); Geol. Soc. Amer. Mem. I54, pp. 133-174.

DYMOND J. and EKLUND W. (1978) A microprobe study of metalliferous sediment components. Earth Planet. Sci. Lett. 40, 243251.

DYMOND J., LYle M., FinNey B., PiPeR D. Z., MURPHY K., CONARD $R$. and PISIAS N. (1984) Ferromanganese nodules from MANOP Sites H, S, and R: Control of mineralogical and chemical composition by multiple accretionary processes. Geochim. Cosmochim. Acta 48, 931-949.

EDMOND J. M., von Damm K. L., MCDuFf R. E. and Measures C. I. (1982) Chemistry of hot springs on the East Pacific Rise and their effluent dispersal. Nature 297, 187-191.

GRAYBEAL A. L. and HEATH G. R. (1984) Remobilization of transition metals in surficial pelagic sediments from the Eastern Pacific. Geochim. Cosmochim. Acta 48, 965-975.

HEATH G. R. and DYMOND J. (1977) Genesis and transformation of metalliferous sediments from the East Pacific Rise, Bauer Deep, and Central Basin, Northwest Nazca Plate. Geol. Soc. Amer. Bull. 88, 723-733.

HEATH G. R. and DYMOND J. (1981) Metalliferous sediment deposition in time and space: East Pacific Rise and Bauer Basin, Northern Nazca Plate. In Nazca Plate: Crustal Formation and Andean Convergence (eds. L. D. KULM et al.); Geol. Soc. Amer. Mem. 154. pp. 175-198.

Hein J. R., Ross C. R., AleXander E., and YeH H-W (1979) Mineralogy and diagenesis of surface sediments from DOMES areas A, B, and C. In Marine Geology and Oceanography of the Pacific Manganese Nodule Province (eds. J. L. BISCHOFF and D. Z. PIPER), pp. 365-396. Plenum.

HENLEY S. (1981) Nonparametric Geostatistics. Applied Science, $145 \mathrm{p}$.

HOFFERT M., KARPOFF A. M., SChaAF A. and PAUTOT G. (1979) La Genèse des Nodules de Manganese (ed. C. LALOU), 101, CNRS, Paris.

LEINEN M. and PISIAS N. (1984) An objective technique for determining end-member compositions and for partitioning sediments according to their sources. Geochim. Cosmochim. Acta 48, 47-62. 
LISITZIN A. P. (1972) Sedimentation in the World Ocean (ed. K. S. Rodolfo); Soc. Econ. Paleont. Mineral. Spec. Pub. No. 17, pp. 149-162.

LuPTON J. E. and CRAIG H. (1981) A major helium-3 source at $15^{\circ} \mathrm{S}$ on the East Pacific Rise. Science 214, 13-18.

LYLE M. (1976) Estimation of hydrothermal manganese input to the oceans. Geology 4, 733-736.

LYLE M., DYMOND J. and HEATH G. R. (1977) Copper-nickel-enriched ferromanganese nodules and associated crusts from the Bauer Basin, Northwest Nazca Plate. Earth Planet. Sci. Lett. 35, 55-64.

LYNN D. C. and BONATTI E. (1965) Mobility of manganese in diagenesis of deep-sea sediments. Mar. Geol. 3, 457-474.

MiEsCH A. T. (1976) Q-mode factor analysis of geochemical and petrologic data matrices with constant row sums. U.S. Geol. Surv. Prof. Paper 574-G.

MURRAY J. and RENARD A. F. (1891) Deep-sea deposits. In Report of the Scientific Results of the Exploration Voyage of the H.M.S. Challenger, (eds. C. W. THOMPSON and J. MURRAY), H.M.S.O., London, 583p.

OWEN R. M. (1980) Quantitative geochemical models of sediment dispersal patterns in mineralized nearshore environments. Mar. Mineral. 2, 231-249.

PeTtersson H. (1959) Manganese and nickel on the ocean floor. Geochim. Cosmochim. Acta 17, 209-213.

RUHLIN D. E. and OWEN R. M. (1986) The rare earth element geochemistry of hydrothermal sediments from the East Pacific Rise: Examination of a seawater scavenging mechanism. Geochim. Cosmochim. Acta 50, 393-400. 